Portland State University

PDXScholar

\title{
Aerosol Gas-Phase Components from Cannabis E-Cigarettes and Dabbing: Mechanistic Insight and Quantitative Risk Analysis
}

\author{
Jiries Meehan-Atrash \\ Portland State University \\ Wentai Luo \\ Portland State University, wentai@pdx.edu \\ Kevin J. McWhirter \\ Portland State University, kevin.mcwhirter@pdx.edu \\ Robert M. Strongin \\ Portland State University, strongin@pdx.edu
}

Follow this and additional works at: https://pdxscholar.library.pdx.edu/chem_fac

Part of the Chemistry Commons

Let us know how access to this document benefits you.

\section{Citation Details}

Meehan-Atrash, Jiries; Luo, Wentai; McWhirter, Kevin J.; and Strongin, Robert M., "Aerosol Gas-Phase Components from Cannabis E-Cigarettes and Dabbing: Mechanistic Insight and Quantitative Risk Analysis" (2019). Chemistry Faculty Publications and Presentations. 289.

https://pdxscholar.library.pdx.edu/chem_fac/289

This Article is brought to you for free and open access. It has been accepted for inclusion in Chemistry Faculty Publications and Presentations by an authorized administrator of PDXScholar. Please contact us if we can make this document more accessible: pdxscholar@pdx.edu. 


\title{
Aerosol Gas-Phase Components from Cannabis E-Cigarettes and Dabbing: Mechanistic Insight and Quantitative Risk Analysis
}

\author{
Jiries Meehan-Atrash, ${ }^{\dagger}$ Wentai Luo, ${ }^{\dagger,}$ Kevin J. McWhirter, ${ }^{\dagger}$ and Robert M. Strongin*, ${ }^{\dagger}$ (1) \\ ${ }^{\dagger}$ Department of Chemistry and ${ }^{\ddagger}$ Department of Civil and Environmental Engineering, Portland State University, Portland, Oregon \\ 97207-0751, United States
}

\section{Supporting Information}

ABSTRACT: Consumption of cannabis by nontraditional methods has surged since the advent of legalization in North America and worldwide. Inhaling cannabis extracts using vaporizers and via dabbing has risen in popularity, while concerns over product safety have not hindered their proliferation. The work herein is the first step toward assessing the safety of vaporizing and dabbing concentrated cannabis extracts as a function of gas-phase reaction products. The gas-phase thermal degradants of $\Delta^{9}$ tetrahydrocannabinol (THC) have not been previously investigated. It was found that users may be exposed to concerning degradants such as methacrolein, benzene, and methyl vinyl ketone when using cartridge vaporizers and dabbing. It was shown that

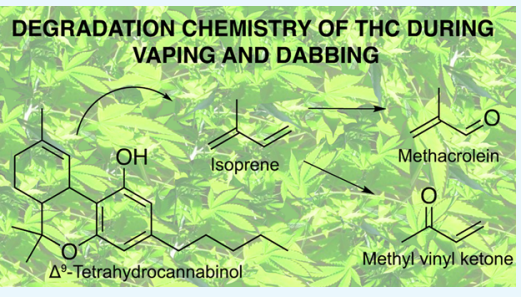
THC alone and mixed with terpenes generated similar degradation products and, most notably, elevated levels of isoprene. Importantly, it was shown that added terpenes led to higher levels of gas-phase products compared to THC alone. To estimate cancer and noncancer risks associated with exposure to these and other degradants, quantitative risk assessment was applied to experimentally determined values for dabbing and vaping and literature-sourced levels of hazardous components in cannabis smoke. Overall, gas-phase aerosol products had significantly lower values in dabbing and vaporizing compared to cannabis smoking, although these results should be interpreted in light of potential variations in degradant levels due to disparate usage patterns and the dangers of the higher aerosol concentration of THC.

\section{INTRODUCTION}

Legalization and increasing social acceptance of cannabis in the United States and worldwide has led to a proliferation of novel cannabis administration methods. Advancement of cannabis extract $(\mathrm{CE})$ production and processing has placed these at the forefront of novel cannabis inhalation methods, and sales of CEs now make up more than $20 \%$ of the retail market share in the Washington state. ${ }^{1}$ Despite their popularity, little work has been done to assess the safety of these novel consumption methods.

Cannabinoids, the constituents responsible for cannabis' psychoactive and medicinal effects, are biosynthesized in trichomes of female cannabis inflorescences. ${ }^{2-4}$ Figure 1 displays the pharmacologically active cannabinoids THC (mp: $<25{ }^{\circ} \mathrm{C}^{5}$ ) and cannabidiol (CBD, mp: 62-63 ${ }^{\circ} \mathrm{C}^{6}$ ), which are biosynthesized as the acid cannabinoids $\Delta^{9}$ -

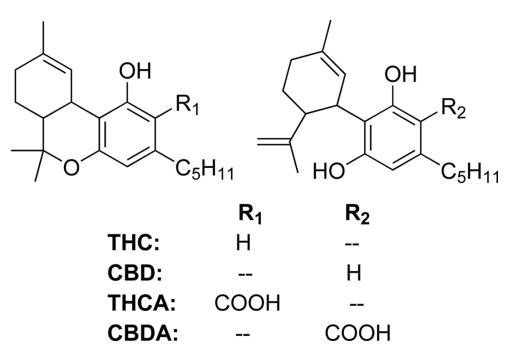

Figure 1. Relevant cannabinoids. tetrahydrocannabinolic acid (THCA, mp $75 \pm 3{ }^{\circ} \mathrm{C}^{7}$ ) and cannabidiolic acid (CBDA, mp $68 \pm 3{ }^{\circ} \mathrm{C}^{8}$ ) that readily decarboxylate upon heating. ${ }^{9}$ Nonpolar solvents (e.g., butane $\mathrm{e}^{10-12}$ and supercritical $\mathrm{CO}_{2}{ }^{13,14}$ ) are used to extract acid cannabinoids in an oleoresin that includes terpenes, waxes, fatty acids, steroids, lignins, etc. ${ }^{15}$ While butane hash oil (BHO, an amber or gold solid ${ }^{10,16}$ ) contains primarily acid cannabinoids, ${ }^{10,11}$ superfluid cannabis extract (SFE) may contain acid or neutral cannabinoids depending on processing methods. Vacuum distillation affords purified neutral cannabinoids allowing manufacturers to tailor cannabinoid and terpene content in the final product commonly referred to as a distillate. ${ }^{17}$ Distillates are often amended with terpenes at 5$15 \%(\mathrm{~m} / \mathrm{m}){ }^{18}$

Three consumption methods/devices for CEs have predominated: dabbing, cartridge vaporizers (CVs), and toploading vaporizers (TLVs). Dabbing involves flash vaporizing a small amount of CE, a dab, on a hot surface, a nail, which is connected to a pipe or water pipe, an oil rig or rig. ${ }^{19}$ A user quickly and immediately inhales aerosol generated when the $\mathrm{dab}$ is placed onto the nail, which may require up to an entire vital capacity for complete capture. ${ }^{11} \mathrm{BHO}$, distillate, and SFE are amenable to dabbing, though $\mathrm{BHO}$ is most common. ${ }^{11,20}$ $\mathrm{CVs}$ are small electronic cigarette-like devices that use battery-

Received: July 23, 2019

Accepted: August 30, 2019

Published: September 16, 2019 
powered resistive heating to aerosolize CEs. A button-activated battery powers an atomizer located in a cartridge preloaded with $\mathrm{CE}$ to generate aerosol a user inhales through a mouthpiece; reliance on wicking necessitates extracts containing neutral THC with added terpenes to decrease viscosity. ${ }^{21}$ TLVs also use a battery to power a resistively heated coil but differ in that users manually place the CE directly onto exposed heating coils in the atomizer ad libitum. ${ }^{22}$ Any extract may be used in TLV. ${ }^{22}$ Both TLV and CV are colloquially referred to as vape pens, and no surveys to date distinguish between the two, categorizing them together as cannabis e-cigarettes or cannabis electronic vapor products (CEVPs). In all these CE consumption methods, carrier liquids such as glycerol, propylene glycol, and medium-chain triglycerides are not typically included as they are considered to be undesirable. ${ }^{23}$

Vaporizing (or vaping) cannabis by any method has gained popularity among recreational and medical users, particularly young adults and teens, ${ }^{24}$ as a less detectable method of using marijuana compared to smoking that is also perceived to be healthier. ${ }^{25-27}$ Vaporizers for cannabis inflorescences ${ }^{28,29}$ have existed long before popularization of CEs, ${ }^{30}$ and terminology used to refer to these (e.g., vaporizers and vapes) has been applied for TLV and CV, which has led to some confusion in the literature. Several studies have investigated prevalence of CEVPs specifically, though many others exist for inflorescence vaporizers. The 2016 National Youth Tobacco Survey ${ }^{31}$ reported that nearly 1 in 11 respondents reported lifetime use of a CEVP, and other state-level surveys report $3.4 \%$ usage among middle-schoolers, ${ }^{32} 5.4-11.4 \%$ for high-schoolers, ${ }^{32,33}$ and $10.7 \%$ for college students. ${ }^{34}$ Sparse data exists on prevalence of dabbing, though it appears to be common among regular cannabis users. Twenty percent of daily/nearly daily cannabis users in the Washington state reported dabbing in the past week, ${ }^{35}$ and $36.5 \%$ of respondents from a Reddit survey of a similar cohort endorsed regular use of dabbing as well. ${ }^{36}$ An internet survey of Twitter posts found that dabbingrelated posts are more prevalent in states with medical marijuana laws, ${ }^{37}$ suggesting that dabbing may grow in popularity as legalization of cannabis expands access to alternative cannabis products.

The thermal behavior of cannabinoids has been studied in the context of the conversion of $\mathrm{CBD}$ to $\mathrm{THC}$ or other potentially psychoactive compounds in smoked marijuana, smoked tobacco with $\mathrm{CBD},{ }^{38-41}$ and pyrolysis of $\mathrm{CBD}$ alone. ${ }^{42,43}$ While searching for potentially psychoactive CBD pyrolysis products, many olivetol derivatives with intact pentyl chains (Figure 2, compds 1-5) 44,45 and other products were found to stem from rearrangement of CBD's terpene moiety (Figure 2, compds 6 and 7), ${ }^{46}$ indicating that this may be particularly labile. Exhaustive in its efforts to identify potential

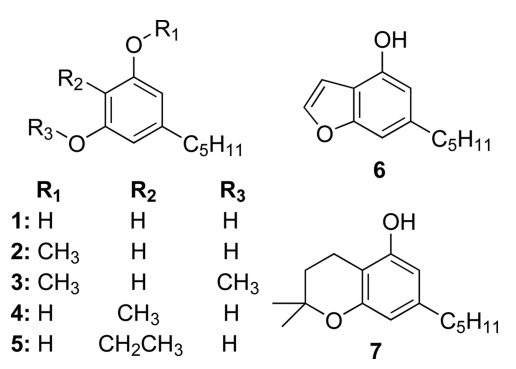

Figure 2. Cannabidiol degradation products. pharmacologically active products, work at the University of Utrecht did not prioritize identifying volatile organic compounds (VOCs). Harmful and potentially harmful constituents (HPHCs) of cannabis smoke have been previously studied, ${ }^{47,48}$ but no information is available concerning pyrolysis or oxidation products of cannabinoids relevant to dabbing or vaping conditions. Moreover, it is not clear if the HPHCs arise from the cannabinoids, terpenes, or any other plant constituents. A recent study described BHO diluted in glycerol and propylene glycol added to a CV-type device, which does not embody the manner in which cannabis concentrates are vaporized. ${ }^{49}$ Evidence-based data is needed to better understand toxicology and routes of administration of these emerging products. We currently do not know, for instance, the aerosol doses of cannabinoids, terpenes, and potentially toxic degradation products being delivered to vulnerable cohorts such as teens and pre-teens or to medical marijuana patients with compromised immune systems.

Quantitative risk assessment (QRA) is an analytically driven risk calculation that pools biological and chemical data to approximate the probability of the incidence of a defined outcome or symptom upon exposure to a given HPHC. QRA has been previously performed for tobacco products, ${ }^{50,52}$ for example, for comparison of "reduced exposure" cigarettes to regular cigarettes. ${ }^{51}$ Cancer risk may be approximated using the excess lifetime cancer risk (ELCR) and noncancer risks using the hazard index (HI). ELCR, the incremental probability of contracting cancer upon specified conditions of exposure to a carcinogen, ${ }^{52}$ is derived from the inhalation unit risk (IUR), an estimate of the increased risk (i.e., above baseline) of developing cancer due to exposure to a $1 \mu \mathrm{g} / \mathrm{m}^{3}$ concentration of a given chemical. ${ }^{53}$ The reference exposure level (REL) is an estimate of an air concentration that is not likely to create an appreciable risk in humans after continuous inhalation and is calculated in reference to a given symptom that occurs after chronic exposure. ${ }^{53}$ Both the IUR and REL may have uncertainties spanning an order of magnitude. A given exposure concentration divided by the REL yields a hazard quotient (HQ) wherein $\mathrm{HQ}>1$ indicates that the threshold of toxic effects on the target system is surpassed. ELCR and HQ values for individual chemicals are summed to yield total ELCR $\left(\mathrm{ELCR}_{\mathrm{T}}\right)$ and $\mathrm{HI}$, respectively, which may be used to guide policy decisions regarding environmental cleanup projects and consumer products. ${ }^{52}$

Previously, our lab had investigated thermal degradation products of terpenes that are present in CEs when exposed to dabbing conditions. ${ }^{19}$ We hypothesize that cannabinoids will generate similar degradation products given their terpene backbone. Given the restricted availability of marijuana derivatives for research, it was possible only to synthetically recreate the $\mathrm{CE}$ product distillate by mixing analytical-grade THC with a terpene aromatherapy mix of cannabis cultivar Fire OG in a ratio of 9:1 THC:terpenes. Herein, we report an investigation of the chemical makeup of aerosol gas phases (GPs) obtained by dabbing pure THC and this synthetic distillate (SND) in addition to vaping SND in a CV device at three power levels commonly used. Adsorption/thermal desorption gas chromatography-mass spectrometry (ATDGCMS) is used to quantify target VOC analytes, and other aerosol GP components are estimated using a nontarget analysis approach. Identified components provide mechanistic insight into the thermal degradation of cannabinoids. Quantitative risk assessment (QRA) calculations are applied 
Table 1. Selected GP Components Identified in Dabbing and CV Vaping Using ATD-GCMS ${ }^{a}$

\begin{tabular}{|c|c|c|c|c|c|}
\hline component, unit & THC dab & SND dab & vape, $3.2 \mathrm{~V}$ & vape, $4.0 \mathrm{~V}$ & vape, $4.8 \mathrm{~V}$ \\
\hline methacrolein, $\mu \mathrm{g}$ & $2.7 \pm 0.8$ & $12 \pm 0.82$ & $5.6 \times 10^{-3}$ & $3.2 \times 10^{-2}$ & $1.9 \times 10^{-1}$ \\
\hline benzene, ng & $33 \pm 14$ & $360 \pm 120$ & $9.9 \times 10^{-1}$ & $2.7 \times 10^{0}$ & $3.6 \times 10^{1}$ \\
\hline xylenes, $\mu \mathrm{g}$ & $0.33 \pm 0.20$ & $0.85 \pm 0.30$ & $1.0 \times 10^{-3}$ & $1.5 \times 10^{-2}$ & $1.8 \times 10^{-1}$ \\
\hline toluene, $\mu \mathrm{g}$ & $0.44 \pm 0.22$ & $1.4 \pm 0.42$ & $7.0 \times 10^{-4}$ & $1.0 \times 10^{-2}$ & $1.6 \times 10^{-1}$ \\
\hline styrene, ng & $0.88 \pm 0.72$ & $27 \pm 14$ & $9.3 \times 10^{-2}$ & $2.7 \times 10^{-1}$ & $\mathrm{ND}^{b}$ \\
\hline ethylbenzene, ng & $1.5 \pm 0.99$ & $55 \pm 30$ & $3.7 \times 10^{-2}$ & $2.5 \times 10^{-1}$ & $2.7 \times 10^{0}$ \\
\hline isoprene, $\mu \mathrm{g}$ & $9.6 \pm 1.7$ & $44 \pm 3.5$ & $3.0 \times 10^{-2}$ & $8.3 \times 10^{-1}$ & $6.0 \times 10^{0}$ \\
\hline other $\mathrm{HCs},{ }^{c} \mu \mathrm{g}$ & $5.3 \pm 0.7$ & $21 \pm 11$ & $4.2 \times 10^{-2}$ & $7.2 \times 10^{-1}$ & $7.9 \times 10^{0}$ \\
\hline total VOCs, ${ }^{d} \mu \mathrm{g}$ & $2.0 \times 10^{1}$ & $7.7 \times 10^{1}$ & $9.4 \times 10^{-2}$ & $1.5 \times 10^{0}$ & $1.2 \times 10^{1}$ \\
\hline
\end{tabular}

${ }^{a}$ For THC and SND dabbing, these were quantified by IS calibration and average for duplicate samples and are presented for a single $40 \mathrm{mg}$ dab \pm SEM. Isoprene levels in dabbing were estimated by IS-RF analysis. GP components for vaping at three voltages are from single-puff measurements estimated using IS-RF analysis. ${ }^{b}$ Styrene was not detected in $\mathrm{CV}$ vaping at $4.8 \mathrm{~V}$ due to overlap of alkenic terpene degradation products. ${ }^{c}$ Nontarget HCs not otherwise specified on this table. ${ }^{d}$ Total of all VOCs quantified.

to estimate cancer and noncancer risks from dabbing and CV usage, and the results of which are compared to risks from smoking cannabis using quantitated cannabis smoke components from the literature. ${ }^{55-58}$ To the best of our knowledge, this is the first time the safety of CEVP and dabbing has been studied, and the first time quantitative risk assessment has been used to evaluate the safety of cannabis smoking.

\section{RESULTS}

GP aerosol components generated from dabbing THC and SND were quantified using internal standard (IS)-normalized multipoint calibration of methacrolein, benzene, xylenes, toluene, styrene, and ethylbenzene in duplicate samples, and response factors (RFs) calculated from ISs were used to estimate levels of these components seen from vaping SND in a CV at three voltages (Table 1). Isoprene levels were estimated using internal standard-calculated response factors (IS-RFs) in all cases. A large diversity of other hydrocarbon (HC) components with a majority of alkenes was observed in all GCMS chromatograms acquired, though the spread differed between SND dabbing (Table S1) and THC dabbing samples (Table S2). Levels of the major-occurring VOCs, identified by comparison of mass spectra against those in the National Institute for Standards and Technology (NIST) mass spectrometry database (match qualities of $>70 \%$ ), were estimated by a previously published nontarget analysis method (see Methods and Materials), ${ }^{58,59}$ and the results of which are displayed in Tables S1 and S2. GP components from dabs of $11 \pm 2.5 \mathrm{mg}$ of either THC or SND were measured and scaled up to $40 \mathrm{mg}$ (reported average $\mathrm{dab}^{60}$ ), assuming equivalent sidestream losses of the GP components across different dab sizes. For CV vaping, GP components are presented from single-puff measurements using standard puff topography for ecigarettes. Many oxygenated compounds identified in the THC dabbing chromatograms (2,5-dimethylfuran, 2,3-dimethylacrolein, etc.) were not identifiable in SND dabbing and CV vaping chromatograms. Analysis of selected ion chromatograms of ions relevant to these oxygenated products in SND samples indicates the presence of these THC-specific degradation products, though they were not quantifiable by nontarget analysis due to overlap from vastly more abundant alkenic terpene degradation products. Sample chromatograms from dabbing THC and SND are presented in the Supporting Information (Figures S1 and S2). A sample chromatogram of $\mathrm{CV}$ vaping was not displayed given its similarity to that of SND dabbing.
To make the comparison between the risks associated with $\mathrm{CV}$ vaping, dabbing, and smoking, the level of chronic consumption of each was matched so each would deliver an equivalent daily dose of THC. This was necessary given the lack of information about specific consumption habits for $\mathrm{CV}$ vaping and dabbing but is justified based on literature precedence. Van Dam et al. ${ }^{61}$ reported a significant decrease in daily grams of cannabis consumed in users that switched from smoking to vaporizing flower cannabis, which has a THC delivery efficiency higher than that of smoking, ${ }^{62}$ suggesting that users adjust the quantity consumed to obtain the same THC delivery based on personal preference. Analogous to the pack-year for cigarette smoking, the joint-year has been used as a measure of cannabis consumption widely used in epidemiological studies of cannabis use $e^{63-65}$ and is defined as smoking 1 joint/day over the course of a year. The jointyear was chosen as the reference point to which approximate THC deliveries for dabbing and CV vaping would be matched by the consumption rate ( $\mathrm{CR}$; see Methods and Materials). Assuming a THC content of $17.1 \%{ }^{66}$ in cannabis and a THC transfer efficiency of $43 \%{ }^{62,67}$ during smoking, a standard 0.75 g joint ${ }^{68,69}$ would yield $55 \mathrm{mg}$ of THC, two $40 \mathrm{mg}$ dabs would yield $55 \mathrm{mg}$ of THC assuming a THC content of $90 \%$ and a transfer efficiency of $76 \%,{ }^{70}$ and 20 puffs from a vape pen (at $4.8 \mathrm{~V}$ ) would yield $54 \mathrm{mg}$ of THC assuming an $85 \%$ yield on 4 $\mathrm{mg}$ puffs of cannabis distillate containing $90 \%$ THC $(\mathrm{m} / \mathrm{m})$.

\section{DISCUSSION}

The identification of several carbonyls, aromatics, and isoprene was in line with a previous report from our lab. ${ }^{19}$ Given that all the terpenes tested in Meehan-Atrash et al. ${ }^{19}$ resulted in a comparable array of volatile products, it was hypothesized that isoprene is an intermediate in the degradation of these compounds. Cannabinoids such as THC contain a terpene backbone, and it is not surprising that similar volatile products are generated from dabbing THC, SND, and terpenes alone. ${ }^{19}$ A diversity of degradation mechanisms may occur upon thermal treatment of THC, but the significant levels of isoprene seen when dabbing THC alone indicate that the isoprene formed undergoes oxidation to release methacrolein and methyl vinyl ketone, a mechanism for which has been described in the context of atmospheric oxidation. ${ }^{71,72}$ Isoprene has been previously described as a neutral product formed during fragmentation of THC in electron impact mass spectrometry. ${ }^{73-75}$ The nearly fivefold increase in isoprene released from THC amended with $\sim 10 \%$ terpenes compared 
to THC alone (Table 1) suggests that terpenes release isoprene more readily than THC. Indeed, all identified VOCs form in higher amounts per milligram of product consumed when dabbing SND than from THC alone. Other minor components in CEs (hydrocarbons, fatty acids, flavonoids, phenols, etc. ${ }^{15}$ ) may add to or alter GP degradants of other extract formulations.

The work presented herein represents a preliminary investigation into the GP aerosol components a cannabis consumer may be exposed to when vaping distillate in a $\mathrm{CV}$ or via dabbing. Several identified components are International Agency for Research on Cancer-classified carcinogens, and exposure to these may place a burden on the health of people that use dabbing or vaping to consume cannabis. In an attempt to interpret results in the most relevant way possible to health professionals and consumers alike, components for which toxicological metrics had been previously calculated were applied to a QRA calculation. Despite the rise in alternative cannabis administration methods, cannabis smoking remains to be the more prevalent mode of cannabis consumption to date, ${ }^{30,76,77}$ warranting a systematic comparison between methods of inhalation. Previously quantified components of cannabis smoke were aggregated from the literature ${ }^{54-57}$ and correspondingly applied to the same QRA analysis in a first attempt to compare the relative safety of smoking cannabis to two existing methods of vaporizing distillate.

Results indicate that vaping or dabbing distillates has lower $\mathrm{HI}$ and ELCR than those of cannabis smoking by several orders of magnitude (Table 2). These findings are not

Table 2. Hazard Index and Excess Lifetime Cancer Risk for Smoking, Dabbing, and Vaping at Three Voltages ${ }^{a}$

\begin{tabular}{|c|c|c|c|}
\hline \multicolumn{2}{|c|}{ consumption type } & $\mathrm{HI}$ & ELCR \\
\hline \multicolumn{2}{|c|}{ smoking (inflorescence) } & $2 \times 10^{2}$ & $4 \times 10^{-4}$ \\
\hline \multicolumn{2}{|c|}{ dabbing (distillate) } & $2 \times 10^{-1}$ & $2 \times 10^{-7}$ \\
\hline \multirow[t]{3}{*}{ vaping } & $4.8 \mathrm{~V}$ (distillate) & $4 \times 10^{-2}$ & $2 \times 10^{-7}$ \\
\hline & $4.0 \mathrm{~V}$ (distillate) & $6 \times 10^{-3}$ & $2 \times 10^{-8}$ \\
\hline & $3.2 \mathrm{~V}$ (distillate) & $8 \times 10^{-4}$ & $2 \times 10^{-9}$ \\
\hline
\end{tabular}

${ }^{a} \mathrm{HI}$ and ELCR for each consumption method calculated using eqs $2-5$. HI and ELCR assume consumption of one $0.75 \mathrm{~g}$ joint, two 40 $\mathrm{mg}$ dabs, and 20 puffs from a CV vape for each voltage.

definitive and must be interpreted with caution as they are only a first step toward determining the overall safety of these cannabis inhalation methods. Only GP components were measured in this work and were applied to QRA calculations, which may underestimate risks due to exclusion of potentially toxic particulate phase components. Previous literature indicates that aldehydes/small organics contribute the largest percentage of the total cancer risk among constituents of cigarette smoke, ${ }^{50}$ which appears to hold true for cannabis smoke as well (Table S4). Furthermore, HI and ELCR are only measures of chronic effects and do not indicate relative safety in the context of acute effects, particularly in light of the recent rash of vaping related illnesses, the cause of which has not been fully identified.

Though widely used by regulatory bodies to make evidencebased decisions on environmental risks to human health, quantitative risk assessment has several unavoidable sources of uncertainty, which is currently magnified due to the lack of standardization in the study of cannabis consumption as compared to tobacco. Machine smoking attempts to imitate realistic use but is only an approximation. ${ }^{52}$ In this study, a puff profile set by the Cooperation Center for Scientific Research Relative to Tobacco (CORESTA) for e-cigarettes was chosen given the functional similarity of these devices to e-cigarettes; however, puffing topography for CEVPs has not been studied, which represents another source of systematic error of unknown magnitude in the work herein. When calculating ELCR and HI, it is assumed that $100 \%$ of each component is absorbed and that the total risk is the sum of the risk from each individual component, which may over- or underestimate the total risk. For cigarette smoking, it has been noted that ELCR values underestimate risks when these are compared to epidemiological data. ${ }^{50}$ However, the cancer risk for cannabis smoking calculated herein, which is comparable to that calculated for cigarette smoking, ${ }^{50}$ is in stark contrast to the negligible association between cannabis smoking and cancer. ${ }^{78}$

In regard to noncancer effects, the major contributor to the elevated HI for cannabis smoking, acrolein, could potentially be responsible for the association between cannabis smoking and respiratory symptoms. ${ }^{79,80}$ Given the uncertainty associated with QRA, dabbing HI may exceed unity under altered conditions such as increased nail temperature, which has been shown to linearly increase degradant formation, ${ }^{19}$ or increased terpene content. Ninety-one percent of the HI from dabbing stems from methacrolein; the REL of which stems from chronic respiratory tract effects (Table S3) and has been specifically implicated as the cause of lung injury due to dabbing BHO in a medical case report. ${ }^{81}$ The elevated levels of conjugated dienes (Table S1 and S2) warrant mention as these have been implicated as prohaptens. ${ }^{82}$ The complete absence of detectable acrolein in dabbing and vaping GP warrants mention as it may imply that this cannabis smoke component stems from plant components other than cannabinoids and terpenes.

Despite the reduction in the toxicant yield for CE vaporizers compared to smoking and the corresponding low $\mathrm{HI}$ and ELCR values, the elevated concentration of THC in the total particulate matter (TPM) may have untold physicochemical ${ }^{83}$ and pharmacological effects ${ }^{84}$ on the respiratory system. For example, cannabis smoke with $\sim 1 \%$ THC content was shown to compromise the surface properties of a lung surfactant replacement product ${ }^{83}$ due to intercalation of the hydrophobic THC molecule. The effect of higher concentrations of THC and high-molecular weight terpenes in the aerosol particulate phase and any partitioning 85 of GP dienes and other VOCs into the lung surfactant layer warrants further investigation.

\section{CONCLUSIONS}

ATD-GCMS identified and quantified gaseous degradants using calibrated standards for target analytes, and a nontarget analysis approach was used for other components identified in the chromatograms. Given the similarity of compounds identified in these experiments to those found when dabbing terpenes alone, ${ }^{19}$ GP degradants seen when dabbing THC alone were also assessed. The similarity in degradation products seen, particularly the elevated levels of isoprene seen across the board, suggests an analogous degradation mechanism for cannabinoids and terpenes. Higher levels of terpenes appear to promote increased production of VOCs.

Toxicants measured were applied to a QRA calculation to estimate cancer and noncancer risks for dabbing and vaping with a CV. In order to compare these results with cannabis smoking, cannabis smoke component levels were taken from 

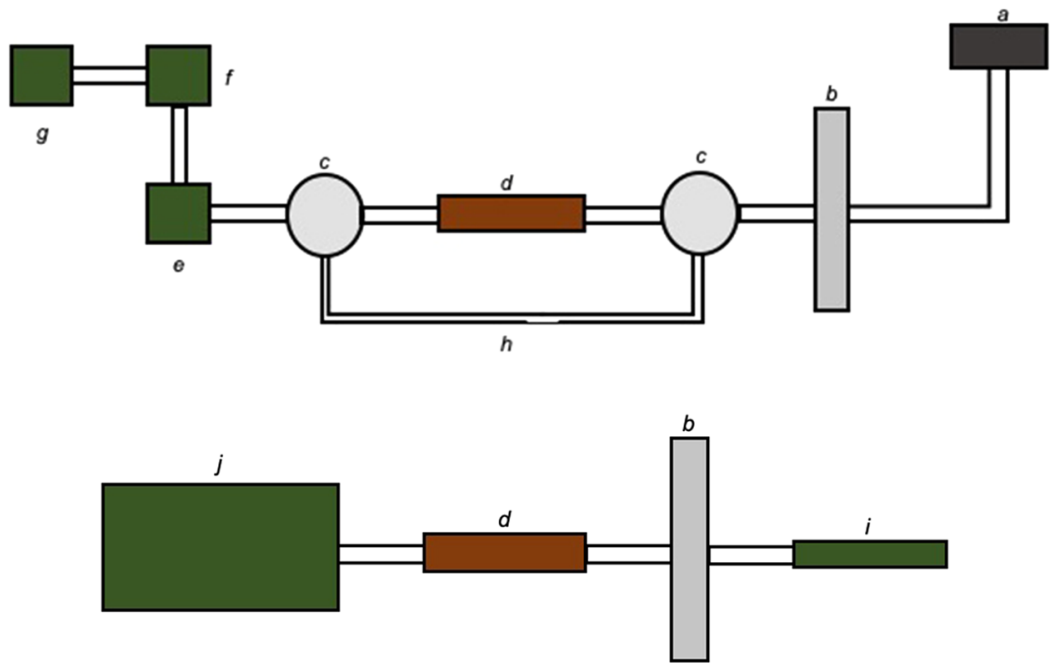

Figure 3. Experimental setups used for dabbing (top) and CV (bottom) vapor collection by ATD-GCMS. Components depicted are the (a) e-nail, (b) CFP holder, (c) three-way stopcock, (d) ATD cartridge, (e) mass flow meter, (f) flow control valve, (g) vacuum source, (h) by-pass line, (i) $\mathrm{CV}$, and (j) CSM.

the literature and applied to a QRA calculation. This represents the first time any degradation products have been identified from vaporizing $\mathrm{CE}$ components and is a first step toward understanding the degradation mechanism of THC via this route of administration. Additionally, the work herein is the first application of QRA to cannabis smoking to the best of our knowledge.

The development of novel cannabis inhalation products has outpaced both basic and applied biomedical research. This has hindered the ability of regulatory agencies from properly informing the public about the safety of these products and their routes of administration. Future work in our labs will focus on identifying other volatile organics that have not yet been detected in the GP, such as formaldehyde and carbon monoxide, and components of the particulate phase that are potentially toxicologically relevant. Further work must assess the biological impact these aerosols have on the respiratory system.

\section{METHODS AND MATERIALS}

Materials. Analytical-grade THC was obtained from Cayman Chemical (Ann Arbor, MI). A terpene aromatherapy mix recreating the scent of cannabis cultivar Fire OG was obtained from Blue River (Oakland, CA) and is referred to hereafter as simply "terpenes." To make SND, terpenes were introduced into THC at $\sim 10 \%$. Verispec $200 \mathrm{ppm}$ Aromatic Hydrocarbons Mixture 16 Components in Methanol EPA 503.1 was obtained from Ricca Chemical Company (Arlington, TX). An isoprene SPEXOrganics Certified Reference Material analytical standard $(1000 \mu \mathrm{g} / \mathrm{mL})$ was obtained from SPEX CertiPrep (Metuchen, NJ).

Sample Collection for Dabbing. An air flow was generated with a Welch 8907 rotary-vane vacuum pump (Mt. Prospect, IL), regulated with a Cole-Parmer PTFE multiturn needle valve (Vernon Hills, IL), and measured with an Aalborg GFM17 mass flow meter (Orangeburg, NY). A flow rate of $400-450 \mathrm{~mL} / \mathrm{min}$ was chosen to minimize breakthrough of volatile components from the adsorption/ thermal desorption (ATD) cartridge while maximizing vapor collection from the e-nail. The ATD cartridge was situated between two Pyrex T-Bore, three-way, glass key stopcocks
(Corning, NY). Vapor was generated on a Jibtronix Corp. Errlectric Concentration Station (Gurnee, IL) e-nail heated to $\sim 370{ }^{\circ} \mathrm{C}$. The temperature used was chosen based on realistic use and was assessed thermographically using a FLIR System T450sc (Wilsonville, OR) as in Meehan-Atrash et al. ${ }^{19}$ A bypass line circumventing the ATD cartridge facilitated sample collection by maintaining a constant backpressure between experiments. All connections were made using 3/8 in. outer diameter ACF0017-F Tygon S3 E-3603 (Saint-Gobain, Malvern, PA). All experiments were performed by collecting GPs generated from a single dab of $11 \pm 2.5 \mathrm{mg}$ of either THC or SND. Figure 3 (top) depicts the experimental setup used for collection of the aerosol GP generated from dabbing.

Sample Collection for CV Vaping. A CH Technologies cigarette smoking machine (CSM, Westwood, NJ) ran a puff program modified from CORESTA with $55 \mathrm{~mL}$ puff volume over a $3 \mathrm{~s}$ puff duration with an additional $1 \mathrm{~s}$ after the conclusion of each puff to clear the lines of aerosol (vaporizer button was only depressed during the $3 \mathrm{~s}$ puffs). Aerosol was generated using a CCell $\mathrm{TH} 2$ oil cartridge (Sneaky Pete vaporizers) loaded with $\mathrm{SND}$ and connected to an Innokin iTaste VV V3.0 variable voltage battery. The atomizer was rated at 1.4-1.5 $\Omega$ according to the digital display provided by the battery. All connections were made using $3 / 8$ in. outer diameter ACF0017-F Tygon S3 E-3603. Vaping experiments were conducted using single puffs at three voltages chosen based on realistic use: $3.2,4.0$, and $4.8 \mathrm{~V}$, which consumed $1-$ $4 \mathrm{mg}$ of SND per puff. Figure 3 (bottom) depicts the experimental setup used for collection of the aerosol GP generated from vaping.

Adsorption/Thermal Desorption Gas Chromatography-Mass Spectrometry. GP samples were collected through a $47 \mathrm{~mm}$ Cambridge filter pad (CFP, GE Healthcare) onto an ATD cartridge, which contains $100 \mathrm{mg}$ of 35/60 mesh Tenax TA and $200 \mathrm{mg}$ of $60 / 80$ mesh Carbograph $1 \mathrm{TD}$ (Camsco Inc., Houston, TX). ATD sample cartridges were thermally desorbed with a TurboMatrix 650 ATD unit (PerkinElmer, Waltham, MA). Twenty nanograms of fluorobenzene, $18.6 \mathrm{ng}$ of toluene- $d_{8}, 21.7 \mathrm{ng}$ of 4-bromofluorobenzene, and $20.3 \mathrm{ng}$ of 1,2-dichlorobenzene- $d_{4}$ were added automatically to all cartridges as ISs prior to desorption. The 
ATD unit thermally desorbed the ATD cartridges for $10 \mathrm{~min}$ at $285{ }^{\circ} \mathrm{C}$ with a He desorption flow of $40 \mathrm{~mL} / \mathrm{min}$, a split flow of $10 \mathrm{~mL} / \mathrm{min}$, and the desorption stream was trapped at -10 ${ }^{\circ} \mathrm{C}$ on an intermediate "Tenax trap." Thermal desorption of this intermediate trap occurred at $295^{\circ} \mathrm{C}$ and 35 psi constant pressure of $\mathrm{He}$ on a split flow of $12 \mathrm{~mL} / \mathrm{min}$ for $4 \mathrm{~min}$. Through a $1 \mathrm{~m}$ long and $0.25 \mathrm{~mm}$ i.d. deactivated fused silica transfer line $\left(235^{\circ} \mathrm{C}\right)$, the unsplit portion of the stream was passed on to a $60 \mathrm{~m}$ length, $0.25 \mathrm{~mm}$ i.d., and $1.4 \mu \mathrm{m}$ film thickness Agilent (Santa Clara, CA) DB-VRX capillary GC column mounted in an Agilent 7890A GC. The GC was interfaced to an Agilent 5975C MS in impact ionization at 70 $\mathrm{eV}$ in the positive ion mode. GC oven temperature was held at $45^{\circ} \mathrm{C}$ for $10 \mathrm{~min}$, programming to $190^{\circ} \mathrm{C}$ at $12{ }^{\circ} \mathrm{C} / \mathrm{min}$, held at $190{ }^{\circ} \mathrm{C}$ for $2 \mathrm{~min}$, then programming to $240{ }^{\circ} \mathrm{C}$ at $6{ }^{\circ} \mathrm{C} /$ min, held at $240{ }^{\circ} \mathrm{C}$ for $5 \mathrm{~min}$, and then programmed down to $210{ }^{\circ} \mathrm{C}$ at $10^{\circ} \mathrm{C} / \mathrm{min}$. The MS scan range was 34 to $400 \mathrm{amu}$, and the electron multiplier voltage was $1725 \mathrm{~V}$.

Quantification of Components from CV Vaping and Dabbing. An ATD-GCMS IS-normalized multipoint calibration was generated for quantifying select analytes for dabbing experiments. A standardized solution of methacrolein and the components in the Verispec $200 \mathrm{ppm}$ aromatic hydrocarbons mixture were made at concentrations of $6.25-200 \mathrm{ng} / \mu \mathrm{L}$ in serial dilution. An additional solution of $250 \mathrm{ng} / \mu \mathrm{L}$ isoprene was made using the SPEXOrganics Certified Reference Material. Two microliters of each chosen standard solution was spiked through a 0.25 " Swagelok tee onto the inlet end of each ATD cartridge with a flow of $50 \mathrm{~mL} / \mathrm{min}$ of $\mathrm{N}_{2}$ gas. After spiking, the $\mathrm{N}_{2}$ flow was left on for $\sim 7 \mathrm{~min}$ to purge the methanol solvent. Six ATD cartridges were amended with 0 , $3.125,12.5,25,50$, and $100 \mathrm{ng}$ of each component from standard solutions containing methacrolein and the Verispec $200 \mathrm{ppm}$ aromatic hydrocarbons mixture components. An additional cartridge was amended with $500 \mathrm{ng}$ of isoprene only.

IS-RF factors for the 17 analytes used in the multipoint calibration and isoprene were calculated and used to estimate the concentration of these in the ATD-GCMS samples from three cannabis vaping experiments. Analytes in addition to those used in the multipoint calibration were tentatively identified by comparison of their mass spectra against those in the NIST mass spectrometry database. Quantification of some major-occurring alkenes, carbonyls, and aromatics was performed using a nontarget analysis approach based on one described in Fitch et al. ${ }^{58}$ and Allgood et al. ${ }^{59}$ Nontarget analytes were chosen based on abundance, integrated in the total ion chromatogram (TIC), and their molecular formula from the tentative match (all match qualities of $>70 \%$ ) was used to calculate their total ionization cross section $(Q)$ using the regression equation from Fitch et al. ${ }^{58}$ The $Q$ of an IS was used to determine the levels of the nontarget analyte using eq 1 from Allgood et al.: ${ }^{59}$

$$
\frac{A_{\mathrm{a}} / N_{\mathrm{a}}}{A_{\mathrm{IS}} / N_{\mathrm{IS}}}=\frac{Q_{\mathrm{a}}}{Q_{\mathrm{IS}}}
$$

where $A$ is the integrated TIC area and $N$ is the number of moles of the analyte (a) and IS.

Cannabis Smoke Component Literature Review. Literature reports containing pertinent data were searched in multiple scientific databases including but not limited to SciFinder and Web of Science. Values for cannabis smoke
HPHCs from all reports containing quantitative data were used. Smoke component identities and their measured values were pulled from the four references deemed suitable for this analysis. $^{54-57}$ Other relevant information such as puff topography, cannabis consumed per experiment, and joint sizes were also noted. HPHC levels were presented as mass HPHC per joint, ${ }^{56}$ parts per million concentrations, ${ }^{54}$ mass HPHC per gram cannabis consumed, ${ }^{55}$ and mass HPHC per milligram TPM collected. ${ }^{57}$ All component levels identified were converted to microgram HPHC per gram of cannabis using the reported joint size. This was subsequently converted to microgram HPHC per $0.75 \mathrm{~g}$ joint, which was chosen as the standard joint mass. HPHCs were assigned CAS numbers, and levels of identical HPHCs were binned and averaged together.

Quantitative Risk Assessment. Toxicological metrics for cancer and chronic noncancer effects for HPCs identified in the GP of the aerosol from vaping, dabbing, and smoking were searched in relevant databases. The IUR was used for cancer risk assessment, and RELs were used for noncancer effects. IUR values were accessed from the Integrated Risk Information System (IRIS) online database provided by the United State Environmental Protection Agency ${ }^{86}$ and supplemented with values from the California Office of Environmental Health and Hazard Assessment (OEHHA) online chemical database. ${ }^{87}$ REL values were taken as an inhalation reference concentration (RfC) from IRIS ${ }^{86}$ or as a reference value $(\mathrm{ReV})$ from the Texas Commission on Environmental Quality (TCEQ). ${ }^{88}$ Given the high levels of isoprene observed from vaping and dabbing, the IUR value for isoprene was found in the literature ${ }^{89}$ given its absence in IRIS, OEHHA, and TCEQ databases.

Quantitative Risk Assessment for Cancer Effects. ELCR as defined in Marano et al. ${ }^{52}$ for each HPHC $i$ for which an IUR value exists was calculated using eq 2 , adapted from Marano et al.: ${ }^{52}$

$$
\begin{aligned}
& \mathrm{ELCR}_{i}= \\
& \frac{\mathrm{CY}_{i}\left(\frac{\mu \mathrm{g}}{\mathrm{CU}}\right) \times \mathrm{CR}\left(\frac{\mathrm{CU}}{\text { day }}\right) \times \mathrm{ED}(\text { years }) \times \operatorname{IUR}_{i}\left(\frac{\mu \mathrm{g}}{\mathrm{m}^{3}}\right)^{-1} \times \mathrm{EF}\left(\frac{\text { days }}{\text { year }}\right)}{\operatorname{IR}\left(\frac{\mathrm{m}^{3}}{\text { day }}\right) \times \operatorname{AT}_{\mathrm{C}}(\text { days })}
\end{aligned}
$$

where $\mathrm{CY}_{i}$ is the yield for a given gaseous $\mathrm{HPHC}, \mathrm{CU}$ is the consumption unit, $\mathrm{CR}$ is the consumption rate, $\mathrm{ED}$ is the exposure duration, EF is the exposure frequency, IR is the inhalation rate, and $\mathrm{AT}_{\mathrm{C}}$ is the averaging time for cancer effects. CU is a consumption method-dependent unit (vaping: $\mathrm{CU}=$ puffs, dabbing: $\mathrm{CU}=$ dabs, and smoking: $\mathrm{CU}=$ joints $)$. $\mathrm{CY}_{i}$ is the experimentally determined yield of a given HPHC given in micrograms per CU. As per United States Food and Drug Administration recommendations, ${ }^{52} \mathrm{ED}$ is taken as the difference of the default lifetime expectancy of 70 years ${ }^{52}$ and the age of initiation, which for cannabis consumption is taken as 16 years based on literature precedence. ${ }^{90-96} \mathrm{EF}$ assumes daily consumption at 365.25 days/year. IR is taken as the human reference value of $20 \mathrm{~m}^{3} /$ day. $^{52} \mathrm{AT}_{\mathrm{C}}$ prorates the cumulative intake of the component over a lifetime of 70 years expressed in days (25567.5 days). ${ }^{52}$ Taking the assumption of dose additivity, the $\mathrm{ELCR}_{i}$ for each component may be summed to obtain $\mathrm{ELCR}_{\mathrm{T}}:^{50-52}$

$$
\mathrm{ELCR}_{\mathrm{T}}=\sum_{i} \mathrm{ELCR}_{i}
$$


Quantitative Risk Assessment for Noncancer Effects. $\mathrm{HQ}$ as previously defined, ${ }^{52}$ for a given component $i\left(\mathrm{HQ}_{\mathrm{i}}\right)$ for which an REL exists was calculated using eq 4, adapted from Marano et al.: 52

$$
\mathrm{HQ}_{i}=\frac{\mathrm{CY}_{i}\left(\frac{\mu \mathrm{g}}{\mathrm{CU}}\right) \times \mathrm{CR}\left(\frac{\mathrm{CU}}{\text { day }}\right) \times \mathrm{ED}(\text { years }) \times \mathrm{EF}\left(\frac{\text { days }}{\text { year }}\right)}{\operatorname{IR}\left(\frac{\mathrm{m}^{3}}{\text { day }}\right) \times \mathrm{AT}_{\mathrm{NC}}(\text { days }) \times \mathrm{REL}_{i}\left(\frac{\mu \mathrm{g}}{\mathrm{m}^{3}}\right)}
$$

where $\mathrm{AT}_{\mathrm{NC}}$ is the averaging time for noncancer effects, which averages component intake over the ED, for a value of 19723.5 days assuming an ED of 54 years. HI, as previously defined, is the sum of HQ for all components for which an REL exists:

$$
\mathrm{HI}=\sum_{i} \mathrm{HQ}_{i}
$$

\section{ASSOCIATED CONTENT}

\section{S Supporting Information}

The Supporting Information is available free of charge on the ACS Publications website at DOI: 10.1021/acsomega.9b02301.

GP components, QRA variables, and sample chromatograms (PDF)

\section{AUTHOR INFORMATION}

\section{Corresponding Author}

*E-mail: strongin@pdx.edu.

\section{ORCID $\odot$}

\section{Robert M. Strongin: 0000-0003-3777-8492}

\section{Author Contributions}

Experimental design: all authors; sample collection: J.M.-A.; ATD-GCMS: W.L. and K.J.M.; data analysis: J.M.-A.; QRA: J.M.-A.; manuscript: J.M.-A. and R.M.S. All authors approved the final version of the manuscript.

\section{Funding}

We thank Portland State University for support. In addition, we thank the National Institute of Health and the Food and Drug Administration for partial support of this work via award no. R01ES025257. The content is solely the responsibility of the authors and does not necessarily represent the views of the National Institute of Health, the Food and Drug Administration, or Portland State University.

\section{Notes}

The authors declare the following competing financial interest(s): All authors except Jiries Meehan-Atrash report no competing financial interests. Jiries Meehan-Atrash reports receiving personal fees from Farm House Tomatoes, a company that has submitted a letter of intent to become a Florida medical marijuana treatment center, but has not yet submitted that application at the time of publishing.

\section{ACKNOWLEDGMENTS}

We would like to acknowledge the United States Drug Enforcement Agency for their support and guidance with security and compliance. We would also like to acknowledge Alisha Ortiz for her help with experiments.

\section{ABBREVIATIONS}

$\mathrm{AT}_{\mathrm{C}}$, averaging time for cancer effects; ATD-GCMS, adsorption/thermal desorption gas chromatography-mass spectrometry; $\mathrm{AT}_{\mathrm{NC}}$, averaging time for noncancer effects; $\mathrm{BHO}$, butane hash oil; CBD, cannabidiol; CBDA, cannabidiolic acid; CE, cannabis extract; CEVP, cannabis electronic vapor product; CFP, Cambridge filter pad; CORESTA, Cooperation Center for Scientific Research Relative to Tobacco; CR, consumption rate; CU, consumption unit; $\mathrm{CV}$, cartridge vaporizer; $\mathrm{CY}_{i}$, component yield; $\mathrm{ED}$, exposure duration; EF, exposure frequency; ELCR, excess lifetime cancer risk; GP, gas phase; HC, hydrocarbon; HI, hazard index; HPHC, harmful or potentially harmful constituent; HQ, hazard quotient; IR, inhalation rate; IRIS, Integrated Risk Information System; IS-RF, internal standard-calculated response factor; IS, internal standard; IUR, inhalation unit risk; NIST, National Institute of Standards and Technology; OEHHA, California Office of Environmental Health and Hazard Assessment; $Q$ total ionization cross section; QRA, quantitative risk assessment; REL, reference exposure level; $\mathrm{ReV}$, inhalation reference value; RF, response factor; RfC, inhalation reference concentration; SFE, superfluid cannabis extract; SND, synthetic distillate; TCEQ, Texas Commission on Environmental Quality; THC, $\Delta^{9}$-tetrahydrocannabinol; THCA, $\Delta^{9}$-tetrahydrocannabinolic acid; TIC, total ion chromatogram; TLV, top-loading vaporizer; TPM, total particulate matter; VOC, volatile organic compound

\section{REFERENCES}

(1) Smart, R.; Caulkins, J. P.; Kilmer, B.; Davenport, S.; Midgette, G. Variation in cannabis potency and prices in a newly legal market: evidence from 30 million cannabis sales in Washington state. Addiction 2017, 112, 2167-2177.

(2) Kim, E.-S.; Mahlberg, P. G. Immunochemical localization of tetrahydrocannabinol (THC) in cryofixed glandular trichomes of Cannabis (Cannabaceae). Am J. Bot. 1997, 84, 336-342.

(3) Sirikantaramas, S.; Taura, F.; Tanaka, Y.; Ishikawa, Y.; Morimoto, S.; Shoyama, Y. Tetrahydrocannabinolic acid synthase, the enzyme controlling marijuana psychoactivity, is secreted into the storage cavity of the glandular trichomes. Plant Cell Physiol. 2005, 46, $1578-1582$

(4) Rodziewicz, P.; Loroch, S.; Marczak, Ł.; Sickmann, A.; Kayser, O. Cannabinoid synthases and osmoprotective metabolites accumulate in the exudates of Cannabis sativa L. glandular trichomes. Plant Sci. 2019, 284, 108-116.

(5) Perrotin-Brunel, H.; Kroon, M. C.; van Roosmalen, M. J. E.; van Spronsen, J.; Peters, C. J.; Witkamp, G. J. Solubility of nonpsychoactive cannabinoids in supercritical carbon dioxide and comparison with psychoactive cannabinoids. J. Supercrit. Fluids 2010, 55, 603-608.

(6) White, J.; Poovendran, D.; Kershaw, S. Cannabidiol (CBD) PreReview Report. Agenda Item 5.2. In.Expert Committee on Drug Dependence Thirty-ninth Meeting., World Health Organization: Geneva, 2017.

(7) Lipomed. THCA-A Specification sheet. https://www.lipomed. $\mathrm{com} /$ index.php?section $=$ mediadir\& $\mathrm{cmd}=$ specification\&eid $=189 \quad$ (accessed July 19, 2019).

(8) Lipomed. Cannabidiolic acid specifications sheet. https://www. lipomed.com/index.php?section=mediadir\& $\mathrm{cmd}=$ specification\&eid= 587 (accessed July 19, 2019).

(9) Perrotin-Brunel, H.; Buijs, W.; van Spronsen, J.; van Roosmalen, M. J. E.; Peters, C. J.; Verpoorte, R.; Witkamp, G.-J. Decarboxylation of $\Delta^{9}$-tetrahydrocannabinol: Kinetics and molecular modeling. J. Mol. Struct. 2011, 987, 67-73. 
(10) Stogner, J. M.; Miller, B. L. Assessing the Dangers of "Dabbing": Mere Marijuana or Harmful New Trend? Pediatrics 2015, 136, 1-3.

(11) Stogner, J. M.; Miller, B. L. The Dabbing Dilemma: A Call for Research on Butane Hash Oil and Other Alternate Forms of Cannabis Use. Subst. Abus. 2015, 36, 393-395.

(12) Cervantes, J. The Cannabis Encyclopedia. Van Patten Publishing: Vancouver, WA, 2015, 546-547.

(13) Perrotin-Brunel, H.; Perez, P. C.; van Roosmalen, M. J. E.; van Spronsen, J.; Witkamp, G. J.; Peters, C. J. Solubility of $\Delta^{9}$ tetrahydrocannabinol in supercritical carbon dioxide: Experiments and modeling. J. Supercrit. Fluids 2010, 52, 6-10.

(14) Perrotin-Brunel, H.; van Roosmalen, M. J. E.; van Spronsen, J.; Verpoorte, R.; Peters, C. J.; Witkamp, G. J. Supercritical fluid extraction of cannabis: experiments and modelling of the process design. ISASF-Graz 2010, 1-6.

(15) Lewis, M. M.; Yang, Y.; Wasilewski, E.; Clarke, H. A.; Kotra, L. P. Chemical Profiling of Medical Cannabis Extracts. ACS Omega 2017, 2, 6091-6103.

(16) Sirius, J. High Times. What is 'Shatter' Marijuana. https:// hightimes.com/grow/shatter-vs-wax-whats-the-difference/ (accessed July 9, 2019).

(17) Miller, M. High Times. Getting Near The Clear: A Guide To Cannabis Distillates. https://hightimes.com/culture/cannabisdistillates/ (accessed July 8, 2019).

(18) Youtube. How to select your THC Vape Cartridge - The Terpene Institute. https://www.youtube.com/watch?v=p5ETFSljZkg (accessed July 9, 2019).

(19) Meehan-Atrash, J.; Luo, W.; Strongin, R. M. Toxicant formation in dabbing: the terpene story. ACS Omega 2017, 2, 6112-6117.

(20) Sirius, J. High Times. What is CO2 Oil?. https://hightimes.com/ grow/what-is-co2-oil/ (accessed July 9, 2019).

(21) Leafly. Everything You Need to Know About Pre-Filled Oil Vape Cartridges. https://www.leafly.com/news/strains-products/what-arepre-filled-cannabis-oil-vape-cartridges (accessed July 9, 2019).

(22) Sirius, J. High Times. Vaping 101: The Proper Hash Oil for Your Pen. https://hightimes.com/dabs/vaping-101-the-proper-hash-oil-foryour-pen/ (accessed July 9, 2019).

(23) Ward, A. Colorado Pot Guide. PG, PEG and Other Vape Cartridge Additives: Are They Safe? https://www.coloradopotguide. $\mathrm{com} /$ colorado-marijuana-blog/article/pg-peg-and-other-vapecartridge-additives-are-they-safe/ (accessed Aug 23, 2019).

(24) Knapp, A. A.; Lee, D. C.; Borodovsky, J. T.; Auty, S. G.; Gabrielli, J.; Budney, A. J. Emerging Trends in Cannabis Administration Among Adolescent Cannabis Users. J. Adolesc. Health 2019, 64, 487-493.

(25) Etter, J. F. Electronic cigarettes and cannabis: an exploratory study. Eur. Addict. Res. 2015, 21, 124-130.

(26) Jones, C. B.; Hill, M. L.; Pardini, D. A.; Meier, M. H. Prevalence and correlates of vaping cannabis in a sample of young adults. Psychol. Addict. Behav. 2016, 30, 915-921.

(27) Popova, L.; McDonald, E. A.; Sidhu, S.; Barry, R.; Maruyama Richers, T. A.; Sheon, N. M.; Ling, P. M. Perceived harms and benefits of tobacco, marijuana, and electronic vaporizers among young adults in Colorado: implications for health education and research. Addiction 2017, 112, 1821-1829.

(28) Hazekamp, A.; Ruhaak, R.; Zuurman, L.; van Gerven, J.; Verpoorte, R. Evaluation of a vaporizing device (Volcano) for the pulmonary administration of tetrahydrocannabinol. J. Pharm. Sci. 2006, 95, 1308-1317.

(29) Lanz, C.; Mattsson, J.; Soydaner, U.; Brenneisen, R. Medicinal Cannabis: In Vitro Validation of Vaporizers for the Smoke-Free Inhalation of Cannabis. PLoS One 2016, 11, No. e0147286.

(30) Hazekamp, A.; Ware, M. A.; Muller-Vahl, K. R.; Abrams, D.; Grotenhermen, F. The Medicinal Use of Cannabis and CannabinoidsAn International Cross-Sectional Survey on Administration Forms. J. Psychoactive Drugs 2013, 45, 199-210.
(31) Trivers, K. F.; Phillips, E.; Gentzke, A. S.; Tynan, M. A.; Neff, L. J. Prevalence of cannabis use in electronic cigarettes among US Youth. JAMA Pediatr. 2018, 172, 1097-1099.

(32) Eggers, M. E.; Lee, Y. O.; Jackson, J.; Wiley, J. L.; Porter, L.; Nonnemaker, J. M. Youth use of electronic vapor products and blunts for administering cannabis. Addict. Behav. 2017, 70, 79-82.

(33) Morean, M. E.; Kong, G.; Camenga, D. R.; Cavallo, D. A.; Krishnan-Sarin, S. High School Students' Use of Electronic Cigarettes to Vaporize Cannabis. Pediatrics 2015, 136, 611-616.

(34) Frohe, T.; Leeman, R. F.; Patock-Peckham, J.; Ecker, A.; Kraus, S.; Foster, D. W. Correlates of cannabis vape-pen use and knowledge among U.S. college students. Addict. Behav. Rep. 2018, 7, 32-39.

(35) Kilmer, B.; Caulkins, J. P.; Midgette, G.; Dahlkemper, L.; MacCoun, R. J.; Pacula, R. L. Before the Grand Opening: Measuring Washington State's Marijuana Market in the Last Year Before Legalized Commercial Sales; Rand Corporation Research Reports, Drug Policy Research Center: 2013 https://www.rand.org/pubs/research reports/RR466.html.

(36) Sagar, K. A.; Lambros, A. M.; Dahlgren, K. M.; Smith, R. T.; Gruber, S. A. Made from concentrate? A national web survey assessing dab use in the United States. Drug Alcohol Depend. 2018, 190, 133142.

(37) Daniulaityte, R.; Nahhas, R. W.; Wijeratne, S.; Carlson, R. G.; Lamy, F. R.; Martins, S. S.; Boyer, E. W.; Smith, G. A.; Sheth, A. "Time for dabs": Analyzing Twitter data on marijuana concentrates across the U.S. Drug Alcohol Depend. 2015, 155, 307-311.

(38) Mikeš, F.; Waser, P. G. Marihuana Components: Effects of smoking on Dgr9-Tetrahydrocannabinol and cannabidiol. Science 1971, 172, 1158-1159.

(39) Kuppers, F. J. E. M.; Lousberg, R. J. J. C.; Bercht, C. A. L.; Salemink, C. A.; Terlouw, J. K.; Heerma, W.; Laven, A. Cannabis VIII - pyrolysis of Cannabidiol. Structure Elucidation of the Main Pyrolytic Product. Tetrahedron 1973, 29, 2797-2802.

(40) Quarles, W. Toxicology of marijuana: conditions for conversion of cannabidiol to THC upon smoking. Clin. Toxicol. 1973, 6, 211216.

(41) Spronck, H. J. W.; Salemink, C. A.; Alikaridis, F.; Papakadis, D. Pyrolysis of cannabinoids: a model experiment in the study of cannabis smoking. Bulletin on Narcotics 1978, 30, 55-59.

(42) Kuppers, F. J. E. M.; Bercht, C. A. L.; Salemink, C. A.; Lousberg, R. J. J. C.; Terlouw, J. K.; Heerma, W. Cannabis-XV: Pyrolysis of cannabidiol. Structure elucidation of four pyrolytic products. Tetrahedron 1975, 31, 1513-1516.

(43) Spronck, H. J. W.; Lousberg, R. J. J. C. Pyrolysis of cannabidiol. Structure elucidation of a major pyrolytic conversion product. Experientia 1977, 33, 705-706.

(44) Kuppers, F. J. E. M.; Bercht, C. A. L.; Salemink, C. A.; Lousberg, R. J. J. C.; Terlouw, J. K.; Heerma, W. Cannabis : XIV. Pyrolysis of cannabidiol-analysis of the volatile constituents. J. Chromatogr. 1975, 108, 375-379.

(45) Luteyn, J. M.; Spronck, H. J. W.; Salemink, C. A. Cannabis XVIII: Isolation and synthesis of olivetol derivatives formed in the pyrolysis of cannabidiol. Recl. Trav. Chim. Pays-Bas 1978, 97, 187190.

(46) Spronck, H. J. W.; Salemink, C. A. Cannabis XVII: Pyrolysis of cannabidiol. Structure elucidation of two pyrolytic conversion products. Recl. Trav. Chim. Pays-Bas 1978, 97, 185-186.

(47) Tjeerdema, R. S. The pyrolysis of cannabinoids. Rev. Environ. Contam. Toxicol. 1987, 99, 61-81.

(48) ElSohly, H. N.; Elsohly, M. A. Marijuana smoke condensate: chemistry and pharmacology. In Marijuana and the cannabinoids, ElSohly, M. A., Ed. Humana Press: Totowa, New Jersey, 2007, 6796.

(49) Varlet, V.; Concha-Lozano, N.; Berthet, A.; Plateel, G.; Favrat, B.; De Cesare, M.; Lauer, E.; Augsburger, M.; Thomas, A.; Giroud, C. Drug vaping applied to cannabis: is "cannavaping" a therapeutic alternative to marijuana? Sci. Rep. 2016, 6, 25599. 
(50) Fowles, J.; Dybing, E. Application of toxicological risk assessment principles to the chemical constituents of cigarette smoke. Tob. Control 2003, 12, 424-430.

(51) Pankow, J. F.; Watanabe, K. H.; Toccalino, P. L.; Luo, W. T.; Austin, D. F. Calculated cancer risks for conventional and "potentially reduced exposure product" cigarettes. Cancer Epidemiol. Biomarkers Prev. 2007, 16, 584-592.

(52) Marano, K. M.; Liu, C.; Fuller, W.; Gentry, P. R. Quantitative risk assessment of tobacco products: A potentially useful component of substantial equivalence evaluations. Regul. Toxicol. Pharmacol. 2018, 95, 371-384.

(53) United States Environmental Protection Agency, Basic Information about the Integrated Risk Information System. USEPA. https://www.epa.gov/iris/basic-information-about-integrated-riskinformation-system (accessed June 6, 2019).

(54) Bloor, R. N.; Wang, T. S.; Spanăl, P.; Smith, D. Ammonia release from heated 'street' cannabis leaf and its potential toxic effects on cannabis users. Addiction 2008, 103, 1671-1677.

(55) Gieringer, D.; Laurent, J. S.; Goodrich, S. Cannabis Vaporizer Combines Efficient Delivery of THC with Effective Suppression of Pyrolytic Compounds. J. Cannabis Ther. 2004, 4, 7-27.

(56) Moir, D.; Rickert, W. S.; Levasseur, G.; Larose, Y.; Maertens, R.; White, P.; Desjardins, S. A comparison of mainstream and sidestream marijuana and tobacco cigarette smoke produced under two machine smoking conditions. Chem. Res. Toxicol. 2008, 21, 494502.

(57) Maertens, R. M.; White, P. A.; Rickert, W.; Levasseur, G.; Douglas, G. R.; Bellier, P. V.; McNamee, J. P.; Thuppal, V.; Walker, M.; Desjardins, $S$. The genotoxicity of mainstream and sidestream marijuana and tobacco smoke condensates. Chem. Res. Toxicol. 2009, 22, 1406-1414.

(58) Fitch, W. L.; Sauter, A. D. Calculation of Relative Electron Impact Total Ionization Cross Sections for Organic Molecules. Anal. Chem. 1983, 55, 832-835.

(59) Allgood, C.; Orlando, R.; Munson, B. Correlations of relative sensitivities in gas chromatography electron ionization mass spectrometry with molecular parameters. J. Am. Soc. Mass Spectrom. 1990, 1, 397-404.

(60) Raber, J. C.; Elzinga, S.; Kaplan, C. Understanding dabs: contamination concerns of cannabis concentrates and cannabinoid transfer during the act of dabbing. J. Toxicol. Sci. 2015, 40, 797-803.

(61) Van Dam, N. T.; Earleywine, M. Pulmonary function in cannabis users: Support for a clinical trial of the vaporizer. Int. J. Drug Policy 2010, 21, 511-513.

(62) Pomahacova, B.; Van der Kooy, F.; Verpoorte, R. Cannabis smoke condensate III: the cannabinoid content of vaporised Cannabis sativa. Inhalation Toxicol. 2009, 21, 1108-1112.

(63) Hashibe, M.; Morgenstern, H.; Cui, Y.; Tashkin, D. P.; Zhang, Z.-F.; Cozen, W.; Mack, T. M.; Greenland, S. Marijuana use and the risk of lung and upper aerodigestive tract cancers: Results of a population-based case-control study. Cancer Epidemiol. Biomarkers Prev. 2006, 15, 1829-1834.

(64) Hancox, R. J.; Poulton, R.; Ely, M.; Welch, D.; Taylor, D. R.; McLachlan, C. R.; Greene, J. M.; Moffitt, T. E.; Caspi, A.; Sears, M. R. Effects of cannabis on lung function: a population-based cohort study. Eur. Respir. J. 2009, 35, 42-47.

(65) Aldington, S.; Williams, M.; Nowitz, M.; Weatherall, M.; Pritchard, A.; McNaughton, A.; Robinson, G.; Beasley, R. Effects of cannabis on pulmonary structure, function and symptoms. Thorax 2007, 62, 1058-1063.

(66) Chandra, S.; Radwan, M. M.; Majumdar, C. G.; Church, J. C.; Freeman, T. P.; Elsohly, M. A. New trends in cannabis potency in USA and Europe during the last decade (2008-2017). Eur. Arch. Psychiatry Clin. Neurosci. 2019, 269, 5-15.

(67) Van der Kooy, F.; Pomahacova, B.; Verpoorte, R. Cannabis smoke condensate I: the effect of different preparation methods on tetrahydrocannabinol levels. Inhalation Toxicol. 2008, 20, 801-804.

(68) Zhang, L. R.; Morgenstern, H.; Greenland, S.; Chang, S.-C.; Lazarus, P.; Teare, M. D.; Woll, P. J.; Orlow, I.; Cox, B.; Brhane, Y.;
Liu, G.; Hung, R. J. Cannabis smoking and lung cancer risk: Pooled analysis in the International Lung Cancer Consortium. Int. J. Cancer 2015, 136, 894-903.

(69) WHO. Cannabis a health perspective and research agenda; World Health Organization, 1997.

(70) Hädener, M.; Vieten, S.; Weinmann, W.; Mahler, H. A preliminary investigation of lung availability of cannabinoids by smoking marijuana or dabbing $\mathrm{BHO}$ and decarboxylation rate of THC- and CBD-acids. Forensic Sci. Int. 2019, 295, 207-212.

(71) Atkinson, R.; Arey, J. Atmospheric degradation of volatile organic compounds. Chem. Rev. 2003, 103, 4605-4638.

(72) Atkinson, R. Gas-phase Tropospheric Chemistry of Organic Compounds: A Review. Atmos. Environ. 1990, 24, 1-41.

(73) Harvey, D. J. Mass spectrometry of the cannabinoids and their metabolites. Mass Spectrom. Rev. 1987, 6, 135-229.

(74) Holler, J. M.; Smith, M. L.; Paul, S. N.; Past, M. R.; Paul, B. D. Isomerization of delta-9-THC to delta-8-THC when tested as trifluoroacetyl-, pentafluoropropionyl-, or heptafluorobutyryl- derivatives. J. Mass Spectrom. 2008, 43, 674-679.

(75) Terlouw, J. K.; Heerma, W.; Burgers, P. C.; Dijkstra, G.; Boon, A.; Kramer, H. F.; Salemink, C. A. The use of metastable ion characteristics for the determination of ion structures of some isomeric cannabinoids. Tetrahedron 1974, 30, 4243-4248.

(76) Lintzeris, N.; Driels, J.; Elias, N.; Arnold, J. C.; McGregor, I. S.; Allsop, D. J. Medicinal cannabis in Australia, 2016: the Cannabis as Medicine Survey (CAMS-16). Med. J. Australia 2018, 209, 211-216.

(77) Cranford, J. A.; Bohnert, K. M.; Perron, B. E.; Bourque, C.; Ilgen, N. Prevalence and correlates of "Vaping" as a route of cannabis administration in medical cannabis patients. Drug Alcohol Depend. 2016, 169, 41-47.

(78) Huang, Y.-H. J.; Zhang, Z.-F.; Tashkin, D. P.; Feng, B.; Straif, K.; Hashibe, M. An epidemiologic review of marijuana and cancer: an update. Cancer Epidemiol. Biomarkers Prev. 2015, 24, 15-31.

(79) Ghasemiesfe, M.; Ravi, D.; Vali, M.; Korenstein, D.; Arjomandi, M.; Frank, J.; Austin, P. C.; Keyhani, S. Marijuana use, respiratory symptoms, and pulmonary function. Ann. Intern. Med. 2018, 169, 106-116.

(80) Meehan-Atrash, J.; Korzun, T.; Ziegler, A. Cannabis inhalation and voice disorders. JAMA Otolaryngol, Head Neck Surg. 2019, DOI: $10.1001 /$ jamaoto.2019.1986.

(81) Anderson, R. P.; Zechar, K. Lung injury from inhaling butane hash oil mimics pneumonia. Respir. Med. Case Rep. 2019, 26, 171173.

(82) Nilsson, A. M.; Bergström, M. A.; Luthman, K.; Nilsson, J. L. G.; Karlberg, A. T. A conjugated diene identified as a prohapten: Contact allergenic activity and chemical reactivity of proposed epoxide metabolites. Chem. Res. Toxicol. 2005, 18, 308-316.

(83) Davies, M. J.; Birkett, J. W.; Court, O.; Mottram, A.; Zoroaster, F. The impact of cannabis smoke on the performance of pulmonary surfactant under physiologically relevant conditions. Surf. Interface Anal. 2018, 50, 188-197.

(84) Turcotte, C.; Blanchet, M. R.; Laviolette, M.; Flamand, N. Impact of cannabis, cannabinoids, and endocannabinoids in the lungs. Front. Pharmacol. 2016, 7, 317.

(85) Pankow, J. F. A consideration of the role of gas/particle partitioning in the deposition of nicotine and other tobacco smoke compounds in the respiratory tract. Chem. Res. Toxicol. 2001, 14, $1465-1481$

(86) USEPA. Integrated Risk Information System (Online Database of Toxicity Values). United States Environmental Protection Agency: 2018, https://www.epa.gov/iris (accessed June 6, 2019)

(87) CALEPA. Online OEHHA Chemical Database. California Office of Environmental Health and Hazard Assessment, California Environmental Protection Agency: 2019, https://oehha.ca.gov/chemicals (accessed June 6, 2019).

(88) TCEQ. Development Support Documents. Texas Commission on Environmenta Quality. https://www.tceq.texas.gov/toxicology/dsd (accessed June 6, 2019). 
(89) Haney, J. T., Jr.; Phillips, T.; Sielken, R. L., Jr.; Valdez-Flores, C. Development of an inhalation unit risk factor for isoprene. Regul. Toxicol. Pharmacol. 2015, 73, 712-725.

(90) Clark, T. T.; Doyle, O.; Clincy, A. Age of First Cigarette, Alcohol, and Marijuana Use Among U.S. Biracial/Ethnic Youth: A Population-Based Study. Addict. Behav. 2013, 38, 2450-2454.

(91) Hayatbakhsh, R.; Williams, G. M.; Bor, W.; Najman, J. M. Early childhood predictors of age of initiation to use of cannabis: A birth prospective study. Drug Alcohol Rev. 2013, 32, 232-240.

(92) Henchoz, Y.; N'Goran, A. A.; Baggio, S.; Deline, S.; Studer, J.; Gmel, G. Associations of age at cannabis first use and later substance abuse with mental health and depression in young men. J. Subst. Use 2015, 21, 85-91.

(93) Melchior, M.; Bolze, C.; Fombonne, E.; Surkan, P. J.; Pryor, L.; Jauffret-Roustide, M. Early cannabis initiation and educational attainment: is the association causal? Data from the French TEMPO study. Int. J. Epidemiol. 2017, 46, 1641-1650.

(94) Sokol, N. A.; Okechukwu, C. A.; Chen, J. T.; Subramanian, S. V.; Rees, V. W. Maternal Cannabis Use During a Child's Lifetime Associated With Earlier Initiation. Am. J. Prev. Med. 2018, 55, 592602.

(95) O'Connell, T. J.; Bou-Matar, C. B. Long term marijuana users seeking medical cannabis in California (2001-2007): demographics, social characteristics, patterns of cannabis and other drug use of 4117 applicants. Harm Reduct. J. 2007, 4, 16.

(96) Borodovsky, J. T.; Crosier, B. S.; Lee, D. C.; Sargent, J. D.; Budney, A. J. Smoking, vaping, eating: Is legalization impacting the way people use cannabis? Int. J. Drug Policy 2016, 36, 141-147. 